\title{
Estimation of Nucleation and Growth Kinetics of Benzoic Acid by Population Balance Modeling of a Continuous Cooling Mixed Suspension, Mixed Product Removal Crystallizer
}

Gary Morris, ${ }^{\dagger, \S}$ Graham Power, ${ }^{\dagger, \S}$ Steven Ferguson, ${ }^{\dagger, \|}$ Mark Barrett, ${ }^{\dagger,}$ Guangyang Hou, ${ }^{\dagger, \S}$ and Brian Glennon*,†,

†Synthesis and Solid State Pharmaceutical Centre, School of Chemical and Bioprocess Engineering, University College Dublin, Belfield, Dublin 4, Ireland

"APC Ltd, NovaUCD, Belfield Innovation Park, Dublin 4, Ireland 


\section{SUPPORTING INFORMATION}

1. Experimental Setup. Figure S1 shows a schematic diagram of the experimental platform comprising two OptiMax workstations (Mettler Toledo). The configuration was operated in product recycle mode, with one OptiMax unit serving as the feed and product

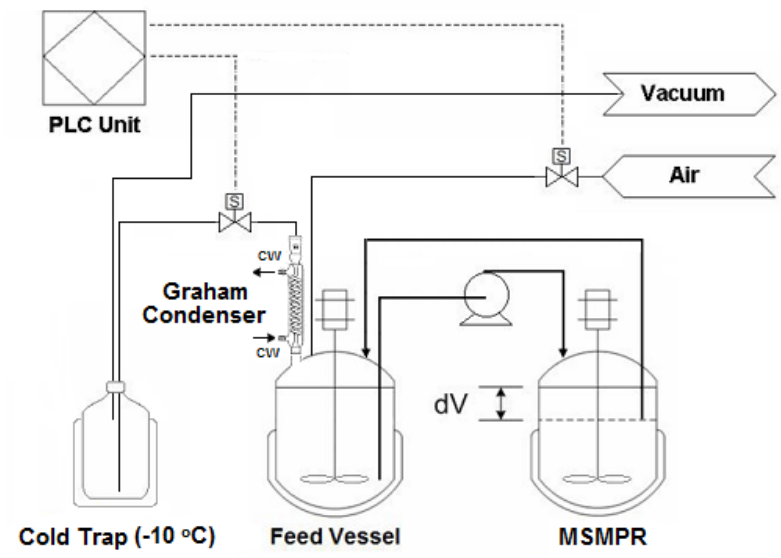

Figure S1. Schematic diagram of the MSMPR experimental setup showing the process configured to operate in product recycle mode.

dissolution vessel and the other as the mixed suspension, mixed product removal (MSMPR) crystallizer. The MSMPR was operated at a volume of $450-500 \mathrm{~mL}$ with 50 $\mathrm{mL}$ of product suspension withdrawn and returned to the feed vessel on an intermittent basis by means of a developed transfer technique. ${ }^{1-3}$ The feed vessel was maintained at $5-15{ }^{\circ} \mathrm{C}$ above the saturation temperature of the feed to ensure rapid dissolution of the returning product crystals and was adjusted depending on the frequency of the returning slug from the crystallizer and slug suspension density. Effective dissolution was confirmed by periodic testing with a focused beam reflectance measurement (FBRM) probe (Mettler Toledo, G400). A peristaltic pump (Watson-Marlow, 323S/D) was used for continuous metering of feed to the crystallizer via heat traced flexible tubing (Watson-Marlow, Pumpsil \#25). Both vessels were equipped with Graham condensers (Chemglass, CG 1830-30). The schematic diagram in Figure S1 shows the integration of one condenser unit into the withdrawal system for the mitigation of solvent loss when executing product transfer. To protect the vacuum pump, a cold trap $\left(-10^{\circ} \mathrm{C}\right)$ was 
incorporated on the vacuum line beyond the condenser to catch any vapour potentially clearing the condenser.

2. Suspension Sample Extraction Technique. Sampling of the crystallizer suspension was performed by exploiting the product transfer technique using the sampling apparatus shown in Figure S2. The procedure involved redirecting the product withdrawal pipe to a

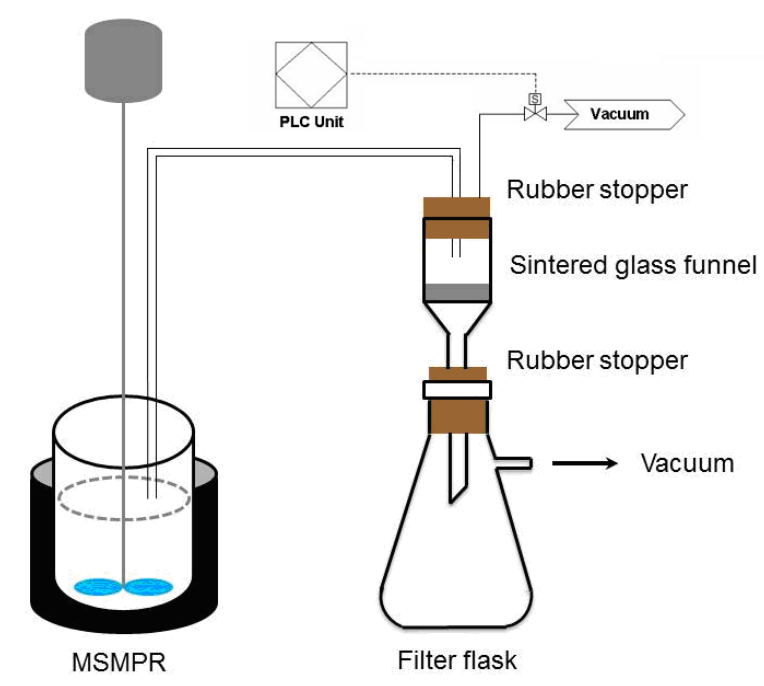

Figure S2. Apparatus used to extract suspension samples from the MSMPR crystallizer.

sealed sintered glass funnel as illustrated in Figure S2, thus interrupting the transfer of product to the feed tank so as to capture a suspension sample. Following sample capture and reconnection of the withdrawal line to the feed vessel, collected suspensions were filtered by applying vacuum to the filter flask for a short time (sufficient to deliquor the filter cake). Mother liquor samples recovered in the filter flask were set aside for concentration determination, and washing (water, $\sim 5^{\circ} \mathrm{C}$ ) of the filter cake was performed using a separate filter flask. Further detail on both the sampling methodology adopted and apparatus used is available in other work. ${ }^{3}$

3. Model Solution Algorithm. A flow diagram of the iterative solution algorithm employed in solving the mathematical process model is shown Figure S3. The solution algorithm solves eqs 1-7 (see main article) simultaneously for a particular combination 
of MSMPR process design variables, $\psi=\left[C_{0}, T, \tau\right]$, and initial value estimates for the set of kinetic parameters to be fitted, $\theta=\left[k_{\mathrm{g} 0}, E_{\mathrm{g}}, g, k_{\mathrm{b}}, j, b\right]$. The model is solved when a suitable value of the MSMPR solute concentration is found by iteration which balances the system of equations.

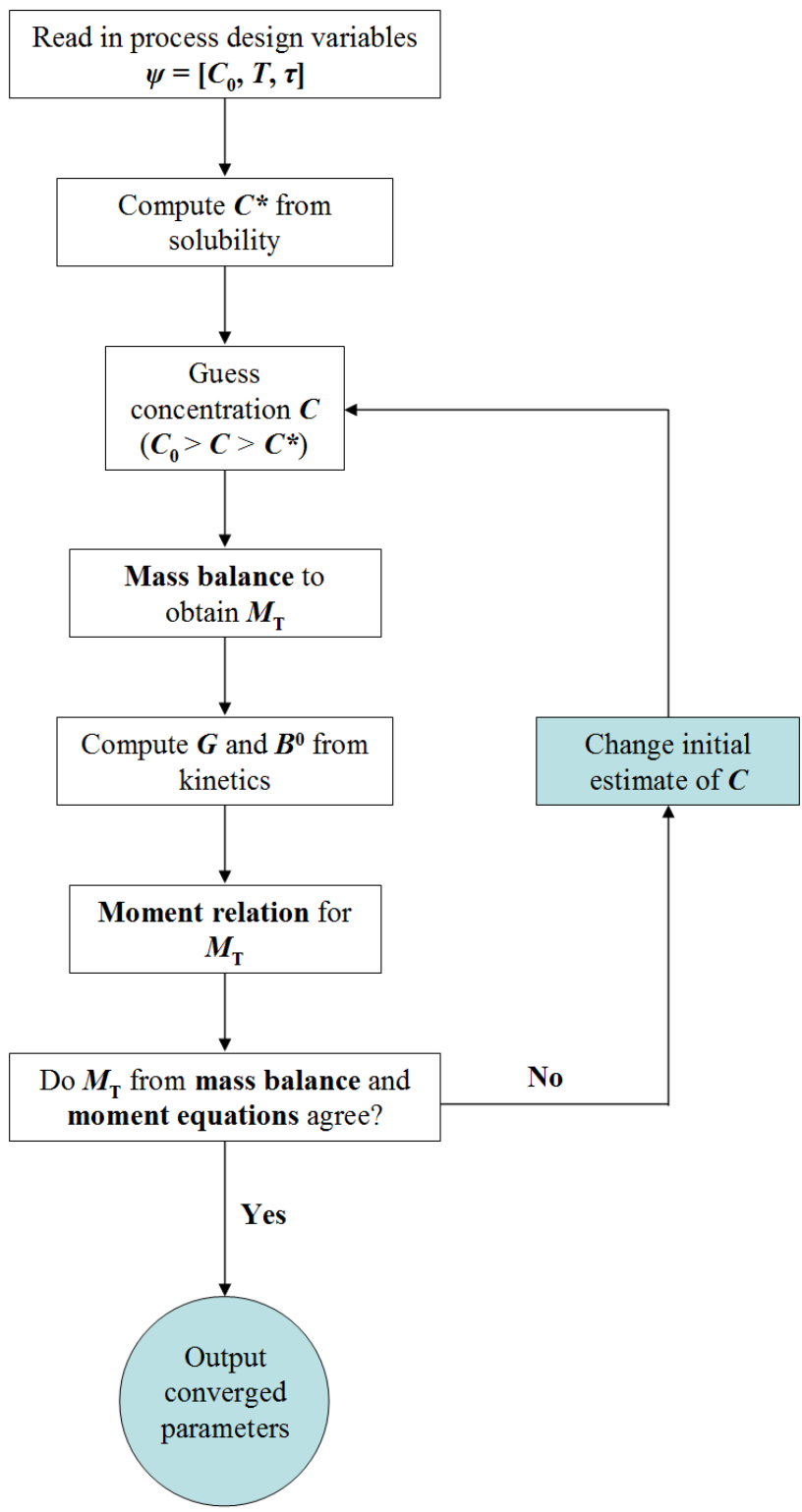

Figure S3. Iterative solution algorithm used to solve the mathematical model of the continuous cooling MSMPR crystallizer. 


\section{AUTHOR INFORMATION}

\section{Corresponding Author}

*E-mail: brian.glennon@ucd.ie. Tel.:+353-1-716-1954. Fax:+353-1-716-1177.

\section{Present Addresses}

${ }^{\S}$ Small Molecule Process Development, APC Ltd, Science Centre South, University College Dublin, Belfield, Dublin 4, Ireland.

"School of Chemical and Bioprocess Engineering, University College Dublin, Belfield, Dublin 4, Ireland.

\section{NOMENCLATURE}

See main article

\section{REFERENCES - SUPPORTING INFORMATION}

(1) Morris, G.; Hou, G.; Barrett, M.; Glennon, B. Design and Characterization of a Continuous Stirred Tank Crystallizer, AIChE Annual Meeting, Pittsburgh, PA, October 28-November 2, 2012, Paper 187c.

(2) Ferguson, S.; Morris, G.; Hao, H.; Barrett, M.; Glennon, B. Chem. Eng. Sci. 2013, $104,44-54$.

(3) Hou, G.; Power, G.; Barrett, M.; Glennon, B.; Morris, G.; Zhao, Y. Cryst. Growth Des. 2014, 14, 1782-1793. 